\title{
IMAGEM(NS) DO SUJEITO-ALUNO DE SECRETARIADO EXECUTIVO ACERCA DE SI E DO PROFISSIONAL DA ÁREA
}

\section{IMAGES OF THE EXECUTIVE SECRETARIAT SUBJECT-STUDENT ABOUT THEMSELVES AND ABOUT THE PROFESSIONAL OF THE AREA}

\section{Raquel Tiemi Masuda Mareco}

Doutoranda em Letras pela Universidade Estadual de Maringá - UEM.

Professora Assistente e como Orientadora de Polo EaD na Faculdade de Tecnologia do Estado de São Paulo - FATEC.

E-mail: rachel.mareco@gmail.com (Brasil)

\section{Verônica Braga Birello}

Doutoranda em Letras/ Linguística - Linha de pesquisa Texto e Discurso da Universidade Estadual de Maringá - UEM. Professora Assistente do Departamento de Letras Modernas na Universidade Estadual de Maringá.

E-mail: ve_mione@hotmail.com 


\section{IMAGEM(NS) DO SUJEITO-ALUNO DE SECRETARIADO EXECUTIVO ACERCA DE SI E DO PROFISSIONAL DA ÁREA.}

\section{RESUMO}

Este artigo tem como objetivo principal investigar quais imagens são sustentadas pela memória discursiva do sujeito-aluno de Secretariado Executivo e acerca de si e do profissional da área. Buscamos, dessa forma, observar as projeções imaginárias do estudante no processo de significação discursiva acerca de si e do profissional atuante em pesquisa aplicada com os acadêmicos do segundo ano do curso em uma universidade estadual do estado do Paraná. Portanto, buscamos responder à seguinte questão de pesquisa: Que imagem(ns) o estudante de Secretariado Executivo tem de si e do profissional da área? Para tanto, procuramos levantar e apresentar os pré-construídos que circulam em nossa sociedade sobre o profissional de secretariado, por meio de uma contextualização histórica. Dessa forma, foi possível apontar como a memória discursiva funciona na sustentação da(s) imagem(ns) do sujeito-aluno ao enunciar sobre si e sobre o profissional. Para tanto, partiremos das teorias da Análise do Discurso francesa com Pêcheux $(1995 ; 1999)$ bem como seus desdobramentos do Brasil com Orlandi (2005). Ainda tomamos por base autores como Achard (1999) e Davallon (1999) para discutir alguns aspectos que dizem respeito à memória discursiva. Para tratar questões relativas às condições de produção específicas do secretariado temos por base trabalhos de Portela, Shumacher e Borth (2013), Birello e Mareco (2013), além de outros autores consideráveis para nossa pesquisa. Nossa pesquisa se caracteriza como um estudo de caso, realizado por meio de uma pesquisa de campo que teve como instrumento um questionário aberto. Nossas análises demonstraram que, mesmo os acadêmicos do curso de secretariado em fase inicial de formação, podem se basear em pré-construídos que não são mais a realidade do mercado de trabalho de sua profissão, promovendo, dessa forma, a perpetuação de uma imagem do secretário como a predominante no século XX e não no século XXI.

Palavras-chave: secretariado executivo; imagem discursiva; análise do discurso. 


\title{
IMAGES OF THE EXECUTIVE SECRETARIAT SUBJECT-STUDENT ABOUT THEMSELVES AND ABOUT THE PROFESSIONAL OF THE AREA
}

\begin{abstract}
This paper aims to investigate which images are supported by the discursive memory of the subjectstudent of Executive Trilingual Secretariat course about themselves and the professional. Therefore, we want to observe the imaginary projections of the student in the discursive signification process about themselves and the professional through a research performed with second year undergraduates of the course at a state university in Paraná. Thus, we aim to answer to this research question: what image does the student have from himself and from the professional? Moreover, we tried to raise and present some pre-built images that circulate in our society about the secretariat professional, through a historical context, showing how the discourse memory works to support these image(s). In order to reach our goal, we are based on the French Discourse Analysis Theories with Pêcheux (1995; 1999) as well as its developments in Brazil with Orlandi (2005). We are also based by authors like Achard (1999) and Davallon (1999) to discuss some aspects related to the discoursive memory. In order to deal with specific issues about the secretariat context, we based ourselves on Portela, Shumacher and Borth (2013), Birello and Mareco (2013), and other major authors that are relevant to our study. Our research is characterized as a case study, by means of a field survey that had an open questionnaire as instrumment. Our analysis have shown that even the students from secretariat course in the initial phase of training can be based on pre-built images that are no longer the reality for the profession in the labor market. This promotes the perpetuation of the predominant image of secretary from the twentieth century, not from the twenty-first century.
\end{abstract}

Keywords: executive trilingual secretariat; discoursive image; discourse analysis. 


\section{Introdução}

O curso de Secretariado Executivo surgiu no Brasil no ano de 1969, na Universidade Federal da Bahia - UFBA. Tal surgimento aconteceu principalmente por conta da procura pelo profissional no mercado de trabalho e sua necessidade de aperfeiçoamento formal.

Vários autores abordam o perfil do profissional de secretariado, como Bortoluzzi e Fávero (2009), ao refletirem sobre o modelo educacional brasileiro e a formação do profissional. Bortoluzzi e Fávero (2009) abordam o perfil secretarial como um equilíbrio entre a prática e a formação e como esse aspecto poderia ser um diferencial para os profissionais da área. Outros autores, como Portela, Shumacher e Borth (2013, p. 38), dentre outros autores, explicam que o novo perfil de secretário traçado a partir dos anos de 1990 vem se consolidando até a atualidade. Esse perfil requer do profissional uma "preocupação com o todo empresarial". Entendemos que essa característica diz respeito à compreensão e acompanhamento da produtividade, a preocupação com os lucros da empresa; saber negociar, participar, assessorar, ter iniciativa, ser pró-ativo, conhecer as competências requeridas para o exercício da profissão etc. Somamos a isso as diferentes possibilidades de atuação do profissional bacharel em Secretariado Executivo, em diversas áreas do mercado de trabalho relacionadas com as disciplinas ofertadas pelos cursos superiores ou com especializações que os bacharéis possam vir a cursar.

Constatamos que com o desenvolvimento da área profissional, o desenvolvimento acadêmico também ocorreu, embora exista ainda bastante espaço para pesquisas na área, como afirma Durante (2012), ao listar a pesquisa como um aspecto que precisa ser desenvolvido embora já esteja em andamento. Isso talvez se deva ao viés prático dos cursos de graduação em secretariado, que ainda investem pouco em pesquisa científica. Durante (2012) propõe que a falta de mestrados e doutorados na área do Secretariado podem contribuir para a falta de pesquisas científicas na área. Entretanto consideramos a pesquisa acadêmica como atividade essencial para ampliar e consolidar conhecimentos na área de secretariado. Assim, neste artigo, investigamos a imagem desse profissional por meio de seus alunos, observando os pré-construídos materializados em seu discurso. Segundo Courtine (1981), o pré-construído é aquilo que faz um discurso parecer evidente, óbvio, natural, ou seja, são discursos anteriores que significam um dado discurso. Em outros termos, Possenti (2009, p. 385) explica que “o pré-construído é um traço, no discurso, de um discurso anterior, que produz um efeito de evidência; é, por um lado, o já dito, e, por outro, o que é uma verdade para uma FD”. A Formação Discursiva (FD) é, segundo Pêcheux (1995, p. 160), 
“Aquilo que, numa conjuntura dada, determinada pelo estado de luta de classes, determina o que pode e deve ser dito (articulado sob a forma de uma arenga, de um sermão, de um panfleto, de uma exposição, de um programa, etc.)".

Como atividade prática, em sala de aula do curso de Secretariado Executivo, observamos que existem alguns pré-construídos que circulam na sociedade e que são mobilizados em alguns enunciados e não em outros. Percebemos que o discurso do sujeito aluno ora o identificava como aluno do curso, ora o identificava como um sujeito sem conhecimentos específicos sobre o universo secretarial. Ao identificar esse jogo de projeções imaginárias agindo de alguma forma na materialidade do discurso procuramos investigar o que as sustenta a seguir. Para analisar essas projeções, contamos com o conceito de formações imaginárias, que são imagens construídas, pelos interlocutores, em antecipação a um discurso.

Assim, temos por objetivo geral observar as projeções imaginárias do estudante de Secretariado Executivo no processo de significação discursiva acerca de si e do profissional do curso. Para tanto, buscamos responder à seguinte questão de pesquisa: Que imagem(ns) o estudante de Secretariado Executivo tem de si e do profissional da área?

Diante de nosso objetivo geral, traçamos três objetivos específicos: a) levantar e apresentar os pré-construídos do Secretariado Executivo como área de formação e atuação profissional; b) compreender o funcionamento da memória na sustentação da(s) imagem(ns) do sujeito-aluno ao falar sobre si e sobre o profissional da área; c) analisar a passagem do lugar social de sujeito-aluno de Secretariado Executivo que enuncia sobre si e sobre o profissional da área para a posição no discurso que permite determinadas imagens e não outras.

Para cumprirmos nossos objetivos, tivemos como base teórico-metodológica a Análise de Discurso de linha francesa, especificamente, a vertente representada por Michel Pêcheux. Abordaremos prioritariamente os conceitos de pré-construído e formações imaginárias.

\section{Descrição Metodológica}

Nossa pesquisa se caracteriza como um estudo de caso, realizado por meio de uma pesquisa de campo, cuja coleta de dados se deu pela documentação direta que, conforme Marconi e Lakatos (2003, p. 186), “constitui-se, em geral, no levantamento de dados no próprio local onde os fenômenos ocorrem. Esses dados podem ser obtidos de duas maneiras: através da pesquisa de campo ou da pesquisa de laboratório". 
Buscando atingir nossos objetivos geral e específicos, temos como material de análise deste trabalho duas perguntas abertas retiradas de questionários aplicados a alunos do segundo ano do curso de Secretariado Executivo de uma universidade pública do estado do Paraná. As perguntas que elaboramos foram direcionadas aos estudantes que cursam o bacharelado em Secretariado Executivo. As respostas dos questionários foram digitadas e tabuladas por questão. O recorte do corpus se deu por meio da identificação das regularidades discursivas no material de análise. As duas perguntas que serviram de base para esse estudo foram:

\section{- O que faz um secretário executivo?}

- O que te fez escolher o curso de Secretariado Executivo?

As perguntas selecionadas para compor nosso material de pesquisa tiveram como critério a apresentação de regularidades discursivas nas respostas das alunas. Analisamos recortes das respostas. $\mathrm{Na} \mathrm{AD}$ trabalhamos com recortes considerando que não precisamos mostrar todo o corpus, visto que trabalhamos com regularidades discursivas, o que tornaria as respostas repetitivas. Mostramos as regularidades e as articulamos com os conceitos sem repetir demasiadamente as regularidades nem apresentar excesso de material de análise.

O curso de Secretariado Executivo, oferecido pela universidade pesquisada tem sua turma composta predominantemente por acadêmicos do sexo feminino. As alunas presentes - dez - na ocasião de aplicação da pesquisa responderam a todas as perguntas do questionário. No momento da aplicação da atividade, as alunas já haviam cursado disciplinas sobre compreensão e produção de textos, línguas estrangeiras, contabilidade, gestão documental e metodologia de pesquisa. No ano de aplicação da entrevista, cursavam disciplinas de línguas estrangeiras e portuguesa, direito, psicologia, ética e técnicas secretariais.

O curso em questão prevê, de acordo com as Diretrizes Curriculares Nacionais, formar profissionais a partir de um currículo interdisciplinar que poderão incluir linhas de formação relacionadas ao gerenciamento, empreendedorismo, assessoramento, consultoria etc., de acordo com a realidade de cada mercado de trabalho. De acordo com as Diretrizes Curriculares Nacionais o curso de Secretariado Executivo deve ter como objetivo formar bacharéis com conhecimento geral e humanístico, capacidade de análise, que saiba interpretar e articular conceitos relacionados à administração pública ou privada de acordo com o esperado pela organização em que se encontra empregado. Algumas habilidades de relacionamento interpessoal também são requisitos para o profissional como receptividade e liderança, iniciativa, criatividade, determinação e vontade de aprender. Aborda ainda aspectos relacionados a tecnologia afirmando que o profissional deve ter 
capacidade para maximizar e otimizar os recursos tecnológicos, entre outras características (Brasil, 2005).

O curso oferecido pela Instituição de Ensino Superior analisado por nós, por sua vez, por meio de texto apresentado em seu site oficial, o perfil de dos alunos que se tornarão profissionais. Segundo o site do curso, o sucesso do profissional bacharel em Secretariado Executivo tem por base sua formação acadêmica, científica e cultural. O acadêmico deve equilibrar seu crescimento profissional e acadêmico devendo estar preparado para mudanças e atento ao mercado de trabalho. Ainda marca o perfil do profissional como gestor, empreendedor, inovador, criativo, dinâmico, negociador, culto, participativo, discreto, conhecedor de vários assuntos como arquivos, cerimonial e protocolo, tecnologias etc. (BRASIL, 2005).

As referidas informações são importantes para - a partir do conhecimento sobre a universidade e o curso pesquisado - analisar as condições de produção dos alunos pesquisados ao enunciarem suas respostas. Acrescentamos que o que está escrito no website do curso está de acordo com as Diretrizes Curriculares Nacionais para o curso, como também explicamos, e que não identificaremos a fonte como o website da IES para que os acadêmicos também não possam vir a ser identificados. Procedemos à análise das respostas obtidas na próxima seção com base na teoria da Análise de Discurso de linha francesa (AD). Realizamos um percurso teórico-analítico, que integra teoria e análise a fim de que não haja separações estanques entre teoria e análise. Na sequência, apresentamos brevemente os conceitos e os aplicamos na análise do corpus deste estudo.

\section{Percurso Teórico-Analítico}

\section{Condições de produção: construção da memória social}

A Análise de Discurso francesa (AD), base teórica e metodológica adotada para esta pesquisa, é um campo da linguística que estuda aspectos ideológicos presentes nos textos. Essa perspectiva surgiu na França na década de 1960, tendo como precursor Michel Pêcheux. Orlandi (2005) afirma que a $\mathrm{AD}$ estabeleceu-se entre três campos do conhecimento: a) a linguística, que entende que a língua tem sua própria materialidade; b) a psicanálise, que entende que o sujeito tem várias faces; c) o marxismo, que tem sua materialidade na história.

Abordamos alguns dos principais conceitos da $\mathrm{AD}$ em nossas análises, tais como: memória discursiva, interdiscurso, condições de produção e formações imaginárias. A memória discursiva "remete ao modo como o trabalho de uma memória coletiva permite a retomada, a repetição, a 
refutação e também o esquecimento desses elementos de saber que são os enunciados" (Possenti, 2009, p. 366). Já o interdiscurso é definido por Fernandes (2007, pp. 65-66) como a presença de diferentes discursos, oriundos de diferentes momentos na história e de diferentes lugares sociais, entrelaçados no interior de uma formação discursiva. Diferentes discursos entrecruzados constitutivos de uma formação discursiva dada; de um complexo com dominante.

Na perspectiva $(A D)$, a relação necessária tanto com as condições imediatas (contexto da leitura) quanto com a exterioridade (condições sócio-históricas) é que evidenciam a incompletude do texto (ORLANDI, 2005) e é o que caracterizamos de "condições de produção", ou seja, acontecimentos e situações propícios para a circulação de um dado discurso. No caso deste trabalho, as condições históricas que a profissão de secretário executivo passou até o momento determinam, em grande parte, que os discursos pré-construídos circulem sem que causem estranhamento, pois ficam "gravados" na memória coletiva. A referida profissão foi regulamentada em 1985, mas, como veremos no decorrer de nossas análises, traz pré-construídos da época em que ainda era considerada uma "profissão".

De acordo com Braick e Mota (2010) a profissão do secretariado remonta a antiguidade clássica, uma vez que Alexandre o Grande se cercava de assessores, que eram responsáveis por sua guarda pessoal, mas que também estavam incumbidos de registrar todas as suas vitórias e estratégias utilizadas em batalhas. Além disso, a profissão dos escribas no Egito deu origem a inúmeras profissões, inclusive a do secretariado. Tal profissional era encarregado de fazer a contabilidade, fiscalização, projetos arquitetônicos, além de ser uma das poucas classes de cidadãos que tinham acesso à língua escrita. Por tudo o que fora explicado por Braick e Mota (2010) pudemos perceber que a profissão não surgiu na contemporaneidade, mas passou por diversas mudanças ao longo do tempo. Birello e Mareco (2013) pontuam que por muito tempo o secretariado foi um ofício, que contava basicamente com as habilidades adquiridas por meio empírico, muitas vezes por meio da observação dos que já desempenhavam tal função. Isso porque não existia acesso aos aspectos teóricos e formais da profissão.

Segundo Ramos (2004), as principais mudanças puderam ser percebidas a partir do séc. XX quando, por ocasião da primeira e segunda guerra mundial, as mulheres passaram a exercer um papel fundamental dentro das empresas, tanto como trabalhadoras operárias, quanto como assessoras executivas. No passado, as funções do profissional do secretariado, embora fossem reduzidas passaram a ser indispensáveis para as grandes companhias. Podemos listar como tarefas fundamentais do profissional da primeira metade do século XX a datilografia de documentos, a 
redação e separação de correspondência, receber e realizar chamadas telefônicas, bem como serviços de copa. Com o passar do tempo os executivos começaram a atribuir aos profissionais tarefas que exigiam conhecimentos técnicos como responder a cartas comerciais, traduzir textos para negociações, gerir a agenda, receber e encaminhar visitantes, servir café. Lima e Cantarotti (2010, p. 97) afirmam: “O perfil exigido do profissional na década de 1960 requeria apenas pessoas com domínio de língua estrangeira e ótima datilografia, sendo que as demais atribuições seriam aprendidas na prática".

Contudo, como nos explicam Portela, Shumacher e Borth (2013), com o desenvolvimento da tecnologia no final do século XX a profissão foi obrigada a acompanhar e a se desenvolver também; por conta disso observamos transformações maiores no perfil desse profissional. Além disso, o mercado de trabalho tem exigido secretários executivos com formação acadêmica específica e direcionada principalmente no Brasil. A tendência do mercado de trabalho sugere a busca pelo profissional capaz de desempenhar diversas funções. Em nosso país, a profissão de Secretário Executivo foi regulamentada por meio da Lei $\mathrm{n}^{\circ} 7.377$ de 1985 e em 1996, com a Lei $\mathrm{n}^{\circ} 9.261$. Birello e Mareco (2013, p. 79) pontuam que esse foi um marco para a profissão no Brasil, pois com a regulamentação, “o que era um ofício passa a ser uma profissão". Para tanto, citamos ainda Sousa Neto (2005) que diferencia ofício de profissão tanto etimologicamente como no entendimento dos dois termos de modo diferente. Sousa Neto (2005) explica que o vocábulo ofício seria derivado do termo latino officiu que seria derivado de um ritual e precisaria de uma oficina para se realizar. Segundo o pesquisador um datilógrafo, um copista, um linotipista realizavam ofícios e esses se desdobraram depois em profissões. Dessa forma, de acordo com as perspectivas apresentadas o ofício seria um "estágio" anterior a consolidação de uma profissão. Podemos entender o ofício enquanto técnicas ritualísticas aplicadas a um processo, muitas vezes mecânico, enquanto profissões são mais abrangentes e requerem ainda outros tipos de conhecimento.

Conforme nos explica Birello (2015) atualmente a capacidade polivalente de atuação do secretariado começa por sua formação, a interdisciplinaridade dentro dos cursos de graduação e o incentivo para a exploração de talentos, aptidões e potencialidades do profissional enquanto acadêmico. É um profissional que precisa apresentar liderança, confiabilidade, criatividade, dinamismo e ainda transitar por diversas áreas. Este alto número de competências e responsabilidades agregam valores e status ao profissional que passa a possuir um alto nível de know-how ampliando, a cada conhecimento adquirido e a cada aptidão potencializada, a sua empregabilidade. Nas universidades, de acordo com pesquisa de Birello e Mareco (2013), os cursos 
de graduação em Secretariado Executivo, por conta de relativa autonomia garantida pelas Diretrizes Curriculares Nacionais podem oferecer disciplinas que abarcam diversas áreas de atuação. Os profissionais, já formados, por sua vez podem continuar se especializando em alguma das diversas áreas de trabalho.

Sendo assim, acreditamos ter levantado alguns dos pré-construídos que circulam junto com a profissão de secretariado, dentro e fora do meio acadêmico. Pensamos que a contextualização histórica da profissão e do curso em nível superior tenham sido abarcadas em nossa breve exposição, pois poderemos, a partir disso, compreender o funcionamento da memória discursiva que sustenta a(s) imagem(ns) dos sujeitos-alunos que responderam aos nossos questionários. Tal contextualização será também fundamental para poder analisar o lugar social e a posição discursiva de tais sujeitos, ao enunciarem sobre si e sobre a profissão.

\section{As formações imaginárias}

Neste tópico, discutimos sobre alguns conceitos relacionados a Análise do Discurso (AD) de linha francesa e seu funcionamento no discurso dos acadêmicos. A AD, de acordo com Debatin (2014), pode ser entendida como um método e teoria que nos auxilia na compreensão, na reflexão, sobre a construção dos efeitos de sentido dos discursos que circulam na sociedade. Para a AD é preciso entender as condições de produção do discurso, os sujeitos, as materialidades significativas e a partir disso pensar as várias possibilidades de significação do que fora dito e do que fora silenciado pelo discurso enunciado. Segundo nos explica Debatin (2014), a AD considera ainda a ideologia, a história, os processos de subjetivação, as lutas de poderes de cada discurso e não apenas o que fora dito ou escrito. Não interessa a este tipo de metodologia saber o motivo pelo qual tal discurso se constituiu e sim entender o como ele significa na sociedade.

Outro conceito fundamental para nossas análises e que também é fruto da Análise do Discurso é o das formações imaginárias. Com base em Pêcheux (1995), podemos dizer que as formações imaginárias são as imagens que os interlocutores fazem de si mesmos, do outro e do objeto do discurso. Além disso, por meio da antecipação, o jogo de imagens também considera as imagens que o locutor acha que seu interlocutor tem dele e as imagens que ele acha que seu interlocutor tem do objeto do discurso. Para Pêcheux (1995, p. 163) quando “o sujeito diz "eu”, o faz a partir de uma inscrição no simbólico e inserido em uma relação imaginária com a "realidade", [...] algo produzido 
após a entrada do sujeito no simbólico e impede que o sujeito perceba ou reconheça sua constituição pelo Outro [...].

Segundo Orlandi (2005), tanto a antecipação quanto as formações imaginárias funcionam em meio a relações de forças. Tais relações são sustentadas pela inscrição do sujeito em diferentes lugares hierarquizados, detentores de maior ou menor poder. Sendo assim, quando o sujeito enuncia não são nem os sujeitos físicos ou seus lugares empíricos que o fazem e sim suas imagens que resultam de projeções.

Ainda de acordo com Orlandi (2005), as condições de produção implicam o que é material, o que é institucional e o que é o imaginário. Nesse jogo de relações são produzidas as imagens dos sujeitos, assim como do objeto do discurso dentro de uma conjuntura sócio-histórica. Isso porque o jogo funciona de forma diferente dependendo das condições de produção de determinado discurso. As condições de produção englobam tudo aquilo que pode e deve ser dito em dado momento e local.

Assim, primeiramente, buscamos identificar no material de análise as regularidades identificadas pela repetição linguística de termos. Observamos nas respostas obtidas com a primeira pergunta - O que faz um secretário Executivo trilíngue? - a recorrência de alguns termos que serão destacados a seguir:

Excede as expectativas como auxiliar direta da chefia, atuando com responsabilidade e compromisso em todas as atuações de uma secretária e ainda é capaz de atuar nas línguas secundárias, inglesa e espanhola (Aluna 1).

Presta assessoria aos diversos níveis hierárquicos de uma organização (Aluna 2).

É o profissional mais próximo do diretor geral e faz tudo desde marcar reunião até fazer uma entrevista de emprego caso seja preciso, ou seja, assessora o chefe até nos mínimos detalhes: trazer café (Aluna 3).

É um profissional multifunção em uma empresa, o braço direito da diretoria. É a pessoa que deve estar sempre pronta para ajudar e ser dinâmica (Aluna 4).

É o profissional que auxilia tudo um pouco, além de ser a pessoa representante da empresa, o rosto associado. Onde possui a ferramenta das línguas para auxiliar no desenvolvimento da empresa (Aluna 5).

Um secretário Executivo é um profissional responsável por atender principalmente a diretoria da empresa, assessorando os mesmos (Aluna 6).

Revista de Gestão e Secretariado - GeSec, São Paulo, v. 7, n. 1, p. 112-149,jan./abr. 2016. 
Um secretário Executivo auxilia os diretores de uma empresa, organizando sua agenda e auxiliando com traduções (Aluna 7).

É o braço direito do chefe, desde cuidar da agenda dele até reuniões com empresas internacionais (Aluna 8).

A principal função da secretária executiva (o) é ser o braço direito do seu diretor, tornando as multifunções mais fácil (sic), e na tomada de decisões, e na relações interdepartamentais (Aluna 9).

Temos que os verbos "auxiliar" e "assessorar" são os mais usados para descrever o profissional do secretariado. Tais verbos remetem aos pré-construídos que representavam a profissão na década de 1960, 1970 e 1980. Segundo Portela, Shumacher e Borth. (2013), nos anos de 1960 ter um secretário a seu dispor era questão de luxo e símbolo de status. Em 1970, o secretário passa a ser visto como membro ativo na gerência da empresa e em 1980 ele forma um time com seu chefe executivo. Vemos que esse pré-construído é mobilizado quando o sujeito-aluno fala sobre a profissão. Ser o "braço-direito", auxiliar, assessorar, constitui um léxico que restringe o profissional a essa "dupla" dentro da empresa, que restringe o profissional a essa pessoa e não a empresa como um todo. Além disso, as outras funções que podem ser executadas pelo profissional são apagadas e silenciadas.

Chama atenção, ainda, a escolha do termo "multifunção". Ao pesquisar o uso do termo descobrimos que a palavra multifunção é utilizada de forma mais comum como "multifuncional" sendo empregada na descrição de máquinas, como impressoras multifuncionais, que podem exercer várias funções. O profissional de Secretariado Executivo é tomado como um sujeito-objeto funcional.

Observamos que o modo pelo qual o profissional foi discursivizado dentro do jogo das formações imaginárias pode ser considerado como o modo da máquina. Ao aproximar o campo lexical que tem por base descrever as características de uma ferramenta podemos dizer que o efeito de sentido do secretário enquanto ferramenta de trabalho. Consideramos essa uma entrada de análise a partir do conceito de interdiscurso e memória, mencionados anteriormente. Segundo Orlandi (2005), temos em funcionamento algo que fala antes, em outro lugar, independentemente, não uma memória empírica, mas uma memória social-discursiva, que torna possível todo o dizer que está na base do já-dito, do dizível.

Dessa forma, podemos analisar o posicionamento do sujeito no discurso, um de nossos objetivos específicos. Isso porque, percebemos que o lugar social do qual o acadêmico enuncia é 
diferente de sua posição discursiva. Seu lugar social seria o de acadêmico do curso de Secretariado Executivo. Pelo que lhe é apresentado no curso, o secretariando aprende, como afirma Torquato (1991, p. 151), que em uma empresa a secretária tende a assumir maiores responsabilidades na administração dos seus respectivos departamentos, passando a gerenciar as questões rotineiras e a assessorar os chefes, recebendo, para isso, maior soma de poderes decisórios. Sendo assim, percebemos que o profissional que gerencia, administra, não poderia ser considerado apenas uma "ferramenta" como uma máquina, ou impressora. Dessa forma, percebemos que ele ocupa outra posição discursiva. Isso pode ser explicado pela prática ideológica dominante que resume o profissional de secretariado a aquele que se presta a tarefas menores como serviços de copa dentro de uma empresa, uma vez que Pêcheux (1995, p. 149) afirma que "só há prática através de e sob uma ideologia" diz ainda que "só há ideologia pelo sujeito e para sujeitos". Observa-se que o que faz com que as alunas pesquisadas se coloquem como ajudantes, multifunção é a constituição ideológico-histórica do seu discurso, considerando que esse discurso é atravessado por discursos jáditos, e reproduzem ideologias que as interpelam e as constituem como sujeitos.

Podemos observar que o pré-construído que sustenta a imagem do estudante acerca do profissional é aquele que marcou a profissão na época das grandes guerras, como explicado anteriormente. Nessa época, as mulheres tornaram-se predominantes na área de atuação, uma vez que os homens tinham ido para o fronte de combate. Todavia, essas mulheres desempenhavam funções ainda operacionais, como a separação de correspondência, atendimento telefônico, datilografia de documentos e cartas além de serviços de copa como preparo de café e outros. Percebemos que essa memória que passou a ser coletiva sustenta as respostas enunciadas pelos alunos.

\section{A memória e a formação da imagem}

A formação da imagem se dá pela memória discursiva que faz reavivar pré-construídos sobre o Secretariado Executivo como área de formação e atuação profissional como os de que o secretário executivo é um executor de comandos, uma ferramenta no escritório não um gestor que pode auxiliar na tomada de decisões e na análise de cenários. Além disso, a expressão "braço-direito" pode remeter novamente à execução, ou seja, apenas uma etapa do processo e não a função secretarial como um todo, que engloba a gestão, o planejamento o controle e a direção como 
propõem as Diretrizes Curriculares Nacionais. Esses são pré-construídos que são mobilizados pelo discurso que tomamos como exemplo.

A memória para a análise do discurso não consiste na memória empírica do sujeito, o que ele se lembra, mas como Pêcheux (1995) assevera, deve ser entendida nos sentidos entrecruzados da memória mítica, da memória social inscrita em práticas e da memória construída do historiador. Para o teórico francês, o que é censura não chega a se inscrever e o que é natural é absorvido. Contudo, existe um lugar do implícito que está ausente pela presença e aparecem na regularização discursiva, sob forma de remissões, de retomadas e de efeitos de paráfrase. Todavia, configuram-se como um novo acontecimento. Tal acontecimento marca relações de força também na memória, que pode absorvê-lo ou dissolvê-lo.

Pêcheux (1995) diz ainda que a imagem é opaca, perde o trajeto da leitura ganhando outros trajetos. Dessa forma a imagem e a memória se dão num jogo de forças de deslocamentos, divisões e retomadas. Sendo assim, nesse outro recorte de nosso corpus buscamos identificar a construção de outras imagens no discurso do sujeito estudante, do mesmo modo pretendemos também identificar a passagem entre lugar social e posição discursiva novamente, mas em outro movimento discursivo. Para tanto, utilizaremos as respostas obtidas com a pergunta: $O$ que te fez escolher o curso de Secretariado Executivo? Tal pergunta foi escolhida por nos fornecer respostas cujos sentidos apontam para a visão que aluno tinha em relação ao curso, seus pré-construídos sobre este.

Anteriormente o sujeito enunciava sobre o profissional de secretariado, contudo, agora deve enunciar sobre si, uma vez que a pergunta direciona para suas razões de escolha do curso. Davallon (1999, p. 24) nos diz a esse respeito:

\footnotetext{
Vemos que entre o simples registro da realidade e a memória social; que entre a reprodução de um acontecimento e a função social de instituição/ re-instituição do tecido social atribuída à memória, há toda a distância que separa a "realidade" do "fato de significação". Faria essa distância pensar, em suma, que a memória, como fato social, comportaria uma dimensão semiótica e simbólica que lhe seria intrínseca.
}

Logo, percebemos que de fato, as memórias são múltiplas. Que a realidade e a memória social não são apenas registros, mas que existe uma distância entre elas. Sendo assim, observamos uma mudança no discurso da maioria dos entrevistados, como mostra o nosso recorte a seguir:

Na verdade, é porque é um curso que tem muitas opções de carreira e eu não possuía uma área que queria com certeza (Aluna 3).

Revista de Gestão e Secretariado - GeSec, São Paulo, v. 7, n. 1, p. 132-149,jan./abr. 2016. 
A diversidade de talentos de um profissional de secretariado, nas línguas estrangeiras e a boa remuneração desse profissional (Aluna 4).

Eu escolhi o curso por já ser fluente em inglês e por já trabalhar na área (Aluna 7).

Escolhi porque gosto das línguas estrangeiras (Aluna 8).

Por ser um curso bem completo onde prepara o profissional para diversos segmentos, além da profissionalização em língua estrangeira (Aluna 9).

No presente recorte, por sua vez, notamos um afastamento da imagem profissional formada anteriormente. Aqui o sujeito estudante, ao falar de si, fala de uma posição diferente daquela assumida anteriormente. Fala sobre a diversidade e a completude do curso, não se resume mais à empresa. Outro aspecto importante mencionado é a afinidade com as línguas estrangeiras oferecidas. Aqui o sujeito, ao pensar sobre o objeto perguntado se identifica com outro préconstruído em relação ao curso apagado até então. Percebemos que o lugar social e a posição discursiva ocupadas são diferentes, pois nesse momento os alunos se aproximam mais daquilo que seria esperado de um estudante do curso. Davallon (1999, p. 24) assevera:

Com os múltiplos jogos que surgem entre a referência, de um lado, a memória social já existente [...] e, de outro lado, à produção de uma nova memória. Pois o registro do "acontecimento" deve constituir memória, quer dizer: abrir a dimensão entre o passado originário e o futuro, [...].

Dessa forma, percebemos que a imagem que é construída sobre si tem por base a memória da profissão na contemporaneidade, não mais a profissão técnica. Assim como Davallon (1999) propõe na relação entre os diferentes jogos, surgem as referências entre o que já é memória e aquilo que se tornará memória. Logo, esse sujeito, ao enunciar fala do secretariado como um curso diversificado, com vários campos de atuação e foco em línguas estrangeiras. Sendo assim, percebemos que a memória coletiva desse grupo social, estudantes do curso, sustenta o pré-construído que trata o secretário como gestor, não como ferramenta de trabalho.

Podemos dizer que existe uma luta de forças entre as duas imagens do profissional. Não há o apagamento completo de nenhuma das imagens, mas há momentos em que uma é mais forte em relação à outra. Num primeiro momento, o lugar social e a posição discursiva dos alunos são diferentes, pois falam da posição da sociedade comum, que não tem acesso ao curso, à diversidade de conteúdos ofertados, do desenvolvimento da profissão. Num segundo momento, quando voltam o olhar para si próprios eles falam do lugar e da posição de alunos do curso, percebem sua 
importância dentro do meio de trabalho em que podem se inserir. Além disso, as possibilidades de carreira aumentam, não se resumem mais a auxílio, a assessoria, ao operacional mecânico, mas mostra a variedade de opções de trabalho e o diferencial do secretário executivo: as línguas estrangeiras. Isso também se dá por conta do que Davallon (1999) sustenta acerca da função da imagem. Para o autor a imagem oferece uma reserva de forças já que mostraria a realidade, sustentando assim a força exercida sobre o público, nesse caso o sujeito-aluno de Secretariado Executivo.

\section{Considerações Finais}

No decorrer deste estudo, depreendemos que as formações imaginárias, que são as imagens que o interlocutor constrói sobre si, sobre o outro e sobre o objeto do discurso, são diferentes dependendo da posição que o acadêmico exerce discursivamente. Retomemos nossos objetivos para demonstrar como foram atingidos: 1) levantar e apresentar os pré-construídos do Secretariado Executivo Trilíngue como área de formação e atuação profissional; 2) compreender o funcionamento da memória na sustentação da(s) imagem(ns) do sujeito-aluno ao falar sobre si e sobre o profissional da área; 3) analisar a passagem do lugar social de sujeito-aluno de Secretariado Executivo Trilíngue que enuncia sobre si e sobre o profissional da área para a posição no discurso que permite determinadas imagens e não outras.

Verificamos que o discurso que as alunas do curso de Secretariado Executivo enunciam tem por base pré-construídos diferentes. Dessa forma, as imagens formadas a partir do processo das formações imaginárias também são diferentes.

Em um primeiro momento, não existe uma identificação entre o aluno e a profissão. Há um afastamento e o aluno olha para o profissional de forma distante, como objeto do discurso; enquanto no segundo momento, o aluno olha para si como objeto do seu discurso. Esse movimento desloca sentidos e faz com que apareça uma imagem do profissional de Secretariado Executivo como uma máquina, como uma ferramenta de trabalho dentro de um escritório, imagem tal que retoma os préconstruídos das décadas de 1960, 1970 e 1980. Logo após, os acadêmicos entrevistados tomam como base os pré-construídos que circulam dentro da academia, como pode ser visto no próprio site oficial do curso dentro da instituição. No decorrer de seu discurso, o secretário executivo produz um discurso no qual se mostra um profissional pró-ativo, independente dentro do escritório; um profissional que possui conhecimentos em diversas áreas e assim tem a capacidade de decidir, de 
gerir processos dentro de seu ambiente de trabalho, que por sua vez não se restringe ao escritório, podendo ser organizador de eventos, interprete, tradutor etc.

Concluímos por meio deste estudo que mesmo os acadêmicos do curso de secretariado em fase inicial de formação podem se basear em pré-construídos que não são mais a realidade do mercado de trabalho de sua profissão - promovendo dessa forma a perpetuação de uma imagem do século XX e não do século XXI. Todavia, nos foi possível perceber que a imagem construída sobre o curso de secretariado Executivo condiz com o pré-construído da atual academia.

Sabemos que nosso estudo é local e por isso pode ser considerado limitado, mas por conta dos resultados encontrados acreditamos que seria interessante repeti-lo ou continuá-lo em escala maior a fim de compreender a fundo a circulação dos enunciados e seus efeitos de sentido. A condução do estudo em escala nacional pode ser interessante para entender se a memória discursiva acerca da profissão se constitui da mesma forma em outras regiões do país e entender se tais enunciados circulam isolados com base em memórias locais ou se os enunciados se repetem de modo a constituir memórias discursivas nacionais.

\section{Referências}

Birello,V. B. \& Mareco, R. T. M. (2013). Supersecretária executiva: Uma análise discursiva sobre as identidades produzidas em um site. Revista Unifamma- Faculdade Metropolitana de Maringá, vol. 13, n. 2, Maringá: Editora Unifamma.

Birello, V. B. (2015). Técnicas secretariais I. Maringá: Unicesumar.

Bortoluzzi, C. de L. \& Fávero, A. A, (2009). Treinamento ou formação: o equilíbrio necessário na configuração do perfil do Secretário Executivo. In Durante, D. G, \& Fávero, A. A. (orgs.) Gestão Secretarial : formação e atuação profissional. Passo Fundo: Ed. Universidade de Passo Fundo.

Braick, P. R. \& Mota, M. B. (2010). História: das cavernas ao terceiro milênio. Vol. 1. (2a ed.) São Paulo: Moderna.

Brasil. Ministério de Educação (2005). Resolução $n^{o}$ 3, de 23 de junho de 2005. Institui as Diretrizes Curriculares Nacionais para o curso de graduação em Secretariado Executivo e dá outras providências. Recuperado em 17 de outubro, 2015, de <http://portal.mec.gov.br/cne/arquivos/pdf/rces003_05.pdf>.

Courtine, J. -J. (1981). Le discours communiste adressé aux chétiens. Langages, vol. 62.

Davallon, J. (1999). A imagem, uma arte da memória? In: Achard, P. et al. Papel da Memória. Trad. José Horta Nunes. Campinas: Pontes. 
Debatin, L., (2014, jan.-abr.) A (des)construção da ideologia no filme "Beleza Americana". Revista de Letras, Artes e Comunicação, Blumenau, vol. 8, n. 1, pp. 2-27, jan./abr. 2014. Recuperado em março, 2016, de http://proxy.furb.br/ojs/index.php/linguagens.

Durante, D. G. (2012). A evolução da profissão secretarial por meio da pesquisa. In: Durante, D. G. (org) A pesquisa em secretariado: cenários, perspectivas e desafios. Passo Fundo: Ed. Universidade de Passo Fundo.

Fernandes, C. A. (2007). Análise do discurso: reflexões introdutórias (2a ed.). São Carlos: Claraluz.

Lima, T. F. \& Cantarotti, A. (2010). A formação e a construção de competências para a atuação do profissional de Secretariado Executivo - um estudo de caso em uma empresa júnior. Revista de Gestão e Secretariado, vol. 1, n. 2. Recuperado em 30 de outubro, 2014, de <http://www.revistagesec.org.br/ojs2.4.5/index.php/secretariado/article/view/17\#.VGCxJfnF9S0>.

Marconi, M. A \& Lakatos E. M. (2003). Fundamentos da metodologia científica (5a ed.). São Paulo: Atlas.

Orlandi, E. P. (2005). Análise de discurso: princípios e procedimentos. Campinas: Pontes.

Pêcheux, M. (1995). Semântica e discurso: uma crítica à afirmação do óbvio. (2a ed. Campinas: Editora da Unicamp.

. (1999). Papel da memória. In: Achard, P. et al. (Org.). Papel da Memória. Tradução e introdução de José Horta Nunes. Campinas: Pontes, pp. 49-57.

Portela, K. C. A.; Shumacher, A. J. \& Borth, M. R. (2013). Ferramentas do Secretariado Executivo (2a ed.). Cuiabá: Dos Autores.

Possenti, Sírio. (2009). Teoria do Discurso: um caso de múltiplas rupturas. In Mussalim, Fernanda \& Bentes, Anna Christina (orgs.). Introdução à Linguística: fundamentos epistemológicos - Vol. 3 (4a ed.). São Paulo: Cortez (pp. 353-391).

Ramos, M. A. N. (2004). O novo perfil da Secretária Executiva. Revista PIBIC, vol. 1, n.1, $\begin{array}{llllll}\text { Recuperado em } & 16 & \text { de } & \text { outubro, }\end{array}$ <http://www.unifieo.br/files/download/site/PIBIC/IniciacaoCientifica/0232tsemr.pdf>.

Sousa Neto, M. F. (2005) O ofício, a oficina e a profissão: reflexões sobre o lugar social do professor. Cadernos Cedes, Campinas, vol. 25, n. 66, pp. 249-259, maio/ago. 2005. Recuperado em 10 de março, 2016, de http://www.scielo.br/pdf/ccedes/v25n66/a07v2566.pdf.

Torquato, G. (1991). Cultura - poder - comunicação e imagem: fundamentos da nova empresa. São Paulo: Pioneira. 